
Military Technical College
Kobry El-Kobbah
Cairo, Egypt

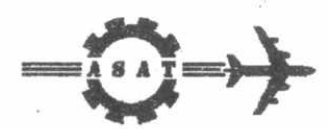

$10^{\text {th }}$ Internationa! Conference

On Aerospace Sciences\&

Aviation Technology

\title{
A FUZZY LOGIC APPROACH TO OUT-OF-STEP DETECTIOIN
}

\author{
M.M. MANSOUR ${ }^{\star \star}$ \\ F.A. KHALIFA* \\ W.S. Sabry*
}

M.S. EL-SAMAHY*

\begin{abstract}
:
This paper presents a synchronous generator out-of-step detection using a Fuzzy Logic (F.L) based approach. After obtaining the convenient state variables (generator prefault loading, difference in acceleration and the average acceleration), three different OS schemes can be designed using the proposed F.L technique. These three schemes correspond to the possible alternatives of selecting two features out of three primary variables. The proposed technique is applied for two different study systems. It is found that once F.L based classifier is applied, accurate and fast decision about the case of the synchronous generator after certain system disturbance is obtained. The developed approach is implemented on Matlab-Simulink for case studies to emulate the real time implementation of the technique.
\end{abstract}

\section{KEY WORDS}

Generator Out-of-Step ; Fuzzy Logic algorithm

\section{NOMENCLATURE}

C.F\% Percentage classification factor.

K.E. Kinetic energy deviation at the instant of fault clearance.

M Moment of inertia.

(M) Number of misclassified sampies.

$\mathrm{N} \quad$ Number of membership functions.

$\mathrm{P}_{\mathrm{m}} \quad$ The prefault generator loading .

$\mathrm{P}_{1} \quad$ Accelerating power at fault inception

$\mathrm{P}_{2} \quad$ Accelerating power after fault clearance

$\Delta \alpha \quad$ Difference in acceleration.

$\alpha_{1} \quad$ Acceleration at fault inception.

$a_{2} \quad$ Acceleration at fault clearance.

$\delta \quad$ Power angle difference between two generators going out-of-step.

$\delta_{\text {limit }} \quad$ Instability threshold power angle value.

$a_{\text {av }} \quad$ Average acceleration during fault.

* Egyptian Armed Forces.

** Professor,Dpt. of Elec. Power and Machines, Faculty of Engineering , Ain Shams University, Cairo, Egypt. e-mail : mmmansour @ ieee.org. 


\section{INTRODUCTION}

In case of fault occurrence the system variables start to oscillate. If the system is stable these oscillations will be damped towards a new operating point. During an out-of-step condition as the swing angle between the generated voltage of a machine change with respect to that of other units in the system the current in any such unit varies in magnitude. The frequency being a function of the reliable rate of slip of the poles in the machine. The resulting high peak currents and off frequency operation can cause winding stresses and pulsating torques which can excite mechanical resonances that could lead to potential damage to the generator and to the turbine generator shafts.

Therefore for an out-of-step condition it is recommended to trip the generator with no delay within the first slip cycle $[1,2]$. Conventional generator out-of-step impedance type relay schemes due to their simplicity; they lack the intelligence to distinguish between various types of disturbances. They are set to insure adequate protection for worst case conditions. Reliable schemes which can distinguish between stable and unstable swings under all system conditions, operate after system torque angle reaches $180^{\circ}$. At this time it is too late to initiate a protective action to maintain stability.

Many non-conventional approaches are proposed to avoid the draw backs of conventional $O . S$ relays [5-10]. In this paper a technique based on Fuzzy Logic (F.L) is introduced. The Fuzzy Logic (F.L) toolbox of Matlab Software [11] is used in the evaluation and generalization of the proposed Fuzzy Logic (F.L) modules. The number as well as the shape of membership functions of the proposed F.L modules were varied for the same set of samples used for evaluation and generalization processes. The performance of each proposed module is evaluated to decide the optimum number and shape.

\section{Conventional Impedance Relays}

The ideal task for out of step relays is to detect transient stability swings on a power system, and then classify them as being stable or un stable. Traditional out-of-step relays perform the detection function by using distance relays and timers. The resulting apparent impedance trajectory is plotted on the Z-plane, suitable impedance zones are determined which classify the cases into stable and unstable categories. A typical out-of-step relay characteristic is shown in Fig.1. [3,4].

\section{FUZZY LOGIC INFERENCE ALGORITHMS}

Fuzzy inference systems (FIS) employ the theory of fuzzy sets and fuzzy if-then rules to derive an output. Various types of FIS are used for fuzzy modeling or fuzzy classification purposes. FIS performs its action in several steps included in Fig.2 $[12,13]$ :

- Fuzzification ( applying the input values to membership functions to obtain degree of relation to each linguistic term).

- Rule evaluation ( firing rule and producing their fuzzy consequents).

- Defuzzification (It is the process of calculating a single-output numerical value for a fuzzy output variable on the basis of the inferred rustling membership function for this variable). 
The investigations described in this paper is done for a Mamdani-type FIS structure, where it is necessary to proceed with the following steps:

1- Choose architecture (type, number) of membership functions for each variable, and set the linguistic term for each membership function.

2- Choose the suitable range (Suppport) of each membership function (according to the training set of each variable).

3- Construct rules' statements .

4- Choose the fuzzy operators (OR,AND).

5-Choose the implication and aggregation operators.

6- Choose the suitable defuzzification method (MOM,COG,COS).

\section{APPLICATION OF FUZZY LOGIC TO OUT-OF-STEP PREDICTION (CASE} STUDY)

The approach of out-of-step prediction based on Fuzzy Logic (F.L) algorithm provides an advantage of early tripping for unstable swing while avoiding tripping on stable swings. This methodology is proposed because it gives a faster decision than the other conventional methods .In the implementation classification error and classification time must be taken into consideration. Two study systems, are considered (a single machine connected to an infinite bus, and a multi-machine system). A load flow calculation is conducted using Matlab-Power System Toolbox to determine the initial conditions of both study systems. The one line diagram as well as the representation by Matlab-Power system Toolbox [11] for the multi-machine understudy system are shown in Fig. 3 and Fig.4. (for single machine connected to infinite bus system refer to [10]).

\subsection{Effective Features Selection Process}

As F.L evaluation data sets is performed [10], It should be mentioned that the input variables have to be normalized in order to reach the input level between $(0-1)$ to overcome the effect of variation of the difference between the largest and the smallest value of each variable $[12,13]$. It is obtained that the most effective features chosen to represent the system state are: average acceleration during fault $\left(\alpha_{\mathrm{av}}\right)$, the Kinetic energy deviation (K.E.), The prefault generator loading $\left(P_{m}\right)$. For the measuring of these features we need a two transducers; one is used to measure the active power $\left(P_{m}\right)$, and the second to measure the speed to produce the (K.E) samples.

In this paper additional factors are taken into consideration in the process of features selection, in the design of the applied FL modules for OS prediction. These factors are simplicity as well as economy of the design. It is well known that the OS is directly proportional to the unbalance between the generated power and the consumed power. The feature that detect that imbalance is the angular acceleration of the rotor, so it is essential to generate the acceleration at major disturbances [at fault inception $\left(\alpha_{1}\right)$, after fault clearance $\left.\left(\alpha_{2}\right)\right]$.

These two variables are obtained as $\alpha_{1}=\left(P_{0}-P_{1}\right) / M, a_{2}=\left(P_{0}-P_{2}\right) / M$. It can be noticed that $\left(\alpha_{1}, \alpha_{2}\right)$ are directly proportional to the accelerating power $\left(P_{1}, P_{2}\right)$, and $(M)$ is constant. In case of normalization they will be equal so we will need to achieve an other variable to over come this problem. The difference between the two accelerations will be defined as $(\Delta \alpha)$, and calculated as $\left(\Delta \alpha=\alpha_{1}-\alpha_{2}\right)$. So the primary variable set will be formed as follows, the first effective feature is the average acceleration $\left(\alpha_{\mathrm{av}}=\left(\alpha_{1}+\alpha_{2}\right) / 2\right)$. 
The second effective feature will be the difference in the acceleration $\left(\Delta \alpha=\alpha_{1}-\alpha_{2}\right)$, the third effective feature will be the pre-fault loading. By applying the two mentioned concepts, for simplicity we will be concerned with only two effective features, and for economy we will choose the two effective features that can be obtained by using the minimum number of transducers, and hence reducing the cost and increase the speed of calculations. It is concluded that the motivation for this simple design is based on one transducer and the local measurements .

\subsection{The Configuration of The Proposed Fuzzy Logic (F.L) Modules}

After the determination of the state variables $\left(\Delta \alpha, \alpha_{a v}, P_{m}\right)$, three different OS schemes can be designed using the proposed FL technique. These three schemes correspond to the possible alternatives of selecting two features out of three primary variables. The second step is to decide in the linguistic variables. These variable transform the numerical values of the input variables to the fuzzy detection module.

The proposed FL-modules have the following design parameters:

1- Type - Mamdani.

2- Input variables are $\left(\alpha_{\mathrm{av}}, \Delta \alpha\right),\left(P_{\mathrm{m}}, \alpha_{\mathrm{av}}\right)$, and $\left(. P_{\mathrm{m}}, \Delta \alpha\right)$.

3- The membership functions for each input variable will be varied in two directions : type ( Triangle, Trapezoid), and number ( for single-machine model it is varied from 3-5, and for the multi-machine system it is varied from 3-9).

4- Fuzzy operators, AND ( $\min )$.

5- Implication operator ( $\min )$.

6- Aggregation (max).

7-Defuzzification process (COG).

\subsection{Evaluation Of The Applied FIS Module:}

In order to check the optimum structure for the designed FIS module we have to analyze the decision (output) of this module against various parameters that possibly affect the operation of that module. In doing so, the number and type of membership functions varied from 3 to 9 for every input sample and the performance of the module is determined to decide the optimum number and type of membership functions for each input variable. Also the same important factor for measurement of the accuracy of the FL module is the number of misclassified samples among the total number of samples. The FL module is evaluated off-line for (70) samples for the single machine model. Table(1) shows the effect of variation of the number as well as the type of membership functions on the performance of the classification process. The FL-classifier is also evaluated off-line for (162) samples for the multi-machine model. Table (2) shows the effect of variation of the number as well as the type of the membership functions on the performance of the classification process for the proposed FIS.

\subsection{Performance Evaluation}

A comparison between the FL technique applied to OS detection and OS detection technique based on feedforward ANN [10] is made. For getting a comparable results in the comparison process, detectors belonging to the two approaches are conducted to the same data sets. However detectors may use different features. Performance evaluation 
should include two main factors. Firstly reliability, which is measured by the number of missed samples during training and testing. Both of the two proposed techniques have comparable classification efficiency, but for the FL technique several of the designed modules scored better efficiency than ANN.

Table(5) and table(6) illustrate a comparison between the best results obtained by the application of both ANN , and FL techniques to OS detection (for both systems under study). Secondly cost, which is directly related to the number of transducers required for the measuring process of the relay. It is found that the ANN technique uses two transducers [10] (active power transducer, speed transducer for calculating the (K.E), while the FL technique uses only one transducer for measuring the active power, which gives lower cost. Finally it is concluded that FL based modules are more suitable for detecting OS condition of synchronous generators .

\section{CONCLUSION}

This paper introduces a synchronous generators out-of-step detection technique based on fuzzy logic algorithms. The based developed approach displays a high efficiency of OS detection. Various F.L topologies have been generalized, compared, and results are presented. Comparing to results obtained by applying ANN to OS detection, it is found that FL based modules are more suitable detecting OS condition of synchronous generators from both reliability and cost points of view.

\section{REFRENCES:}

[1] Imhof J.A. et at., "Out-of-Step Relaying for Generators", Working Group Report, IEEE Trans.Power Appar.Syst.,PAS-96 (1977).

[2] Mansour M.M.," Mutual Effect Between Network Protection And Transient Stability of E.H.V. Power System ", MSc. Thesis in Elec. Eng.,Ain Shams University, (1980).

[3] Anderson P.M.," Power System Protection", The Institute of Electrical and Electronics Engneering, Inc.,(1999).

[4] Paithankar Y.G.,"Transmission Network Protection: Theory and Practice", Marce! Dekker,Inc.,(1998).

[5] Taylor Cowhand Hanar J.M., "A New Out-of-Step Relay With Rate of Change of Apparent Resistance Augmentation", IEEE Trans.,vol.PAS-102,No.3,pp 631639, March (1983).

[6] Reomish W. R. and Wall E. T. , " A New Synchronous Out-of-Step Relay Scheme ", Part I, IEEE Trans, , PAS-104 ,pp. 563 - 572 , march (1985) .

[7] W. R. Reomish and E. T. Wall , "A New Synchronous Out-of-Step Relay Scheme ", Part II , IEEE Trans. , PAS-104, pp. 573 - 582, march (1985)

[8] Ohura Y. ,Suzuki M., Yanagihashi K.," A predictive Out-of-Step Protection System Based on Observation of The Phase Difference Between Substations", IEEE Trans.,vol.5,No.4,pp1695-1704,Nov. (1990).

[9] El-Arabaty A.M., Talaat H.A.,Mansour M.M.,Abdelaziz A.Y.," out-of-step detection based on pattern recognition", International journal of electrical power and energy systems, vol.16,No.4,pp 269-275,Aug.(1994). 
[10] M.M.Mansour, F.A.Khalifa, M.S.El-Samahy" An Intelligent Out-Of-Step Detection Technique", 3rd International Conference On Electrical Engineering (ICEENG), May 2002

[11] Matlab The Language of Technical Computing ,Version 6.0.0.88, Release 12, Mathworks, Inc., September (2000).

[12] J.A.Momoh,K.Tomsovic,"Over View And Literataure Survey of Fuzzy Set Theory in Power Systems", IEEE Trans.on Power Systems, Vol.10, No.3, Aug. 1995.

[13] Kasabov, Nikola K." Foundations of neural Networks , Fuzzy Systems and Knowledge Engineering " Massachusetts Institute of Technology, second printing , (1998)

Table (1) Results of Evaluation of the proposed FIS, Including Variation of Shape and Number of MFs (Samples generated from the single machine model, first training set).

\begin{tabular}{|c|c|c|c|c|c|c|}
\hline Variables & \multicolumn{6}{|c|}{ Efrective features $\left(a_{i v}, \mathrm{Im}\right)$} \\
\hline \multirow{3}{*}{$\begin{array}{l}\text { Shape of } \\
\text { Mirs }\end{array}$} & \multicolumn{6}{|c|}{ Number of Mits } \\
\hline & \multicolumn{2}{|c|}{$N=3$} & \multicolumn{2}{|c|}{$N=4$} & \multicolumn{2}{|c|}{$N=5$} \\
\hline & $\mathbf{M}$ & CF\% & M & CF\% & $\mathbf{M}$ & CF\% \\
\hline Triangle & 4 & $94.3 \%$ & 2 & $97.1 \%$ & 0 & $100 \%$ \\
\hline Trapezoid & 3 & $95.7 \%$ & 2 & $97.1 \%$ & 1 & $98.6 \%$ \\
\hline
\end{tabular}

Table (2) Results of Evaluation of the proposed FIS, Including Variation of Shape and Number of MFs (Samples generated from the multi-machine model ,third training set) .

\begin{tabular}{|c|c|c|c|c|c|c|c|c|}
\hline \multirow{4}{*}{$\begin{array}{l}\text { Shape of } \\
\text { Mrms. }\end{array}$} & \multicolumn{8}{|c|}{ Effective features $\left(\alpha_{a v} \mathrm{P}_{\mathrm{m}}\right)$} \\
\hline & \multicolumn{8}{|c|}{ Namber of Mlits } \\
\hline & \multicolumn{2}{|c|}{$N=3$} & \multicolumn{2}{|c|}{$N=5$} & \multicolumn{2}{|l|}{$N=7$} & \multicolumn{2}{|c|}{$\mathrm{N}=9$} \\
\hline & $\mathbf{M}$ & CF\% & $\mathbf{M}$ & CF\% & $\mathbf{M}$ & CF\% & $\mathbf{M}$ & $\mathrm{CF} \%$ \\
\hline Triangle & 5 & $96.9 \%$ & 3 & $98.15 \%$ & 2 & $98.76 \%$ & 0 & $100 \%$ \\
\hline Trapezoid & 3 & $98.15 \%$ & 2 & $98.76 \%$ & 2 & $98.76 \%$ & 1 & $99.38 \%$ \\
\hline
\end{tabular}


Table (3) Comparison between the best results obtained by the application of both ANN, and FL techniques to OS detection (Single Machine System)

\begin{tabular}{|c|c|c|c|c|c|c|c|c|}
\hline $\begin{array}{l}\text { System } \\
\text { Under }\end{array}$ & \multicolumn{8}{|c|}{ Proposed T echmique for OS Detection } \\
\hline \multirow{5}{*}{$\begin{array}{l}\text { Single } \\
\text { Machine } \\
\text { System }\end{array}$} & \multirow[b]{2}{*}{ ANM } & $\begin{array}{l}\text { Training } \\
\text { Trpes }\end{array}$ & Bfi. Y arrables & Nit & (11) & (B) & (M) & C. $1 \%$ \\
\hline & & $\begin{array}{l}\text { Conv. } \\
\text { Training }\end{array}$ & $\mathrm{KE}, \alpha_{\mathrm{av}}, \mathrm{P}_{\mathrm{m}}$ & 15 & 0.5 & 0.9 & 2 & $95 \%$ \\
\hline & \multirow{3}{*}{ FI. } & Type of Mirs & Varianles & \multicolumn{3}{|c|}{ No. of MTs (N) } & (M) & C. $\mathrm{P} \%$ \\
\hline & & Triangular & \multirow[t]{2}{*}{$\alpha_{\mathrm{av}}, \mathrm{P}_{\mathrm{m}}$} & \multicolumn{3}{|c|}{5} & 1 & $97.5 \%$ \\
\hline & & Trapezoidal & & \multicolumn{3}{|c|}{5} & 1 & $97.5 \%$ \\
\hline
\end{tabular}

Table (4) Comparison between the best results obtained by the application of both ANN, and FL techniques to OS detection (Multi-Machine System)

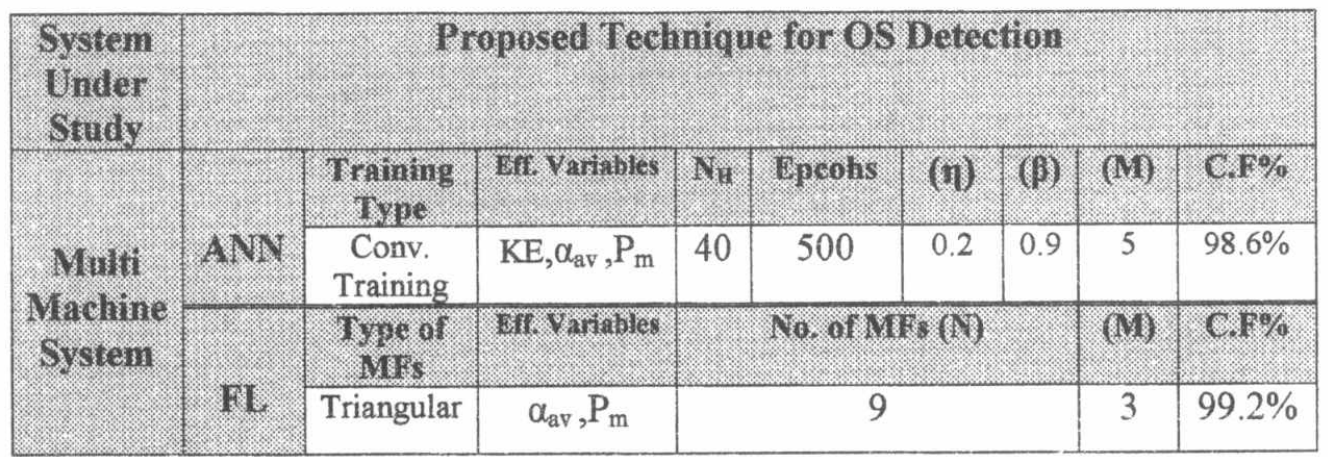




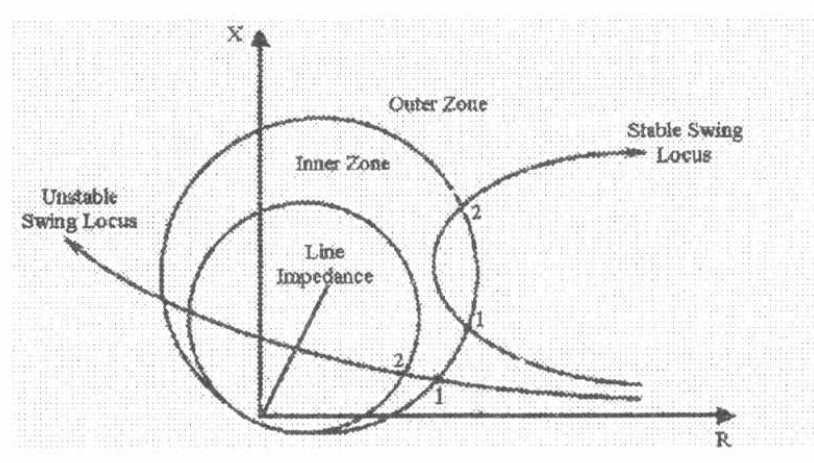

Fig.1 Blocking and Tripping characteristic For Conventional impedance Trajectory Method

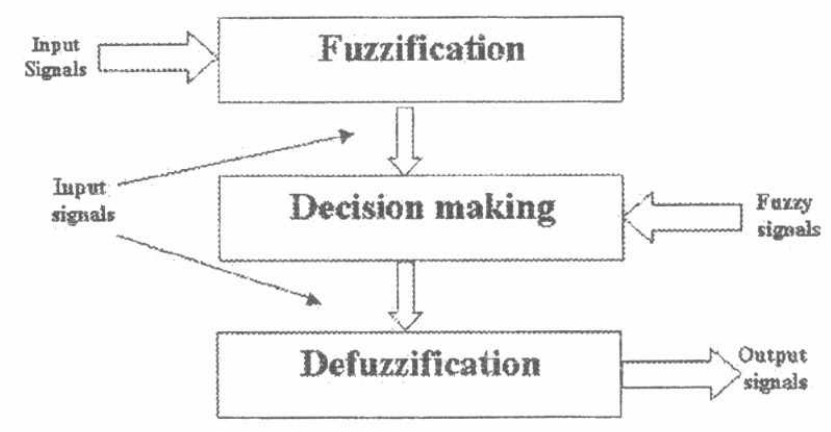

Fig.2 Fuzzy Reasoning System

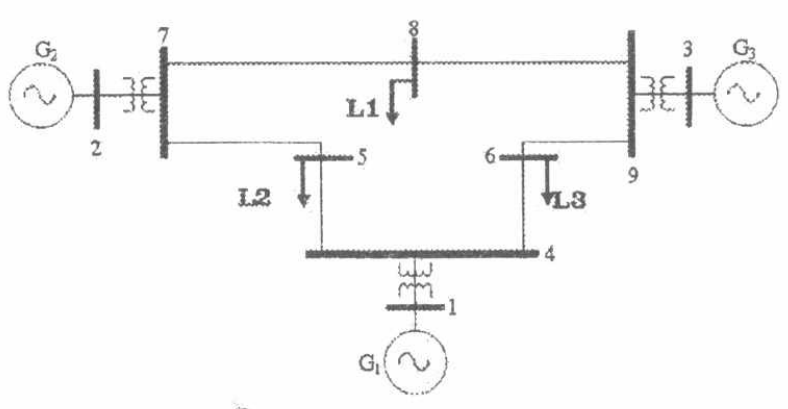

Fig.3 One - Line Diagram Of Case Study (2) 


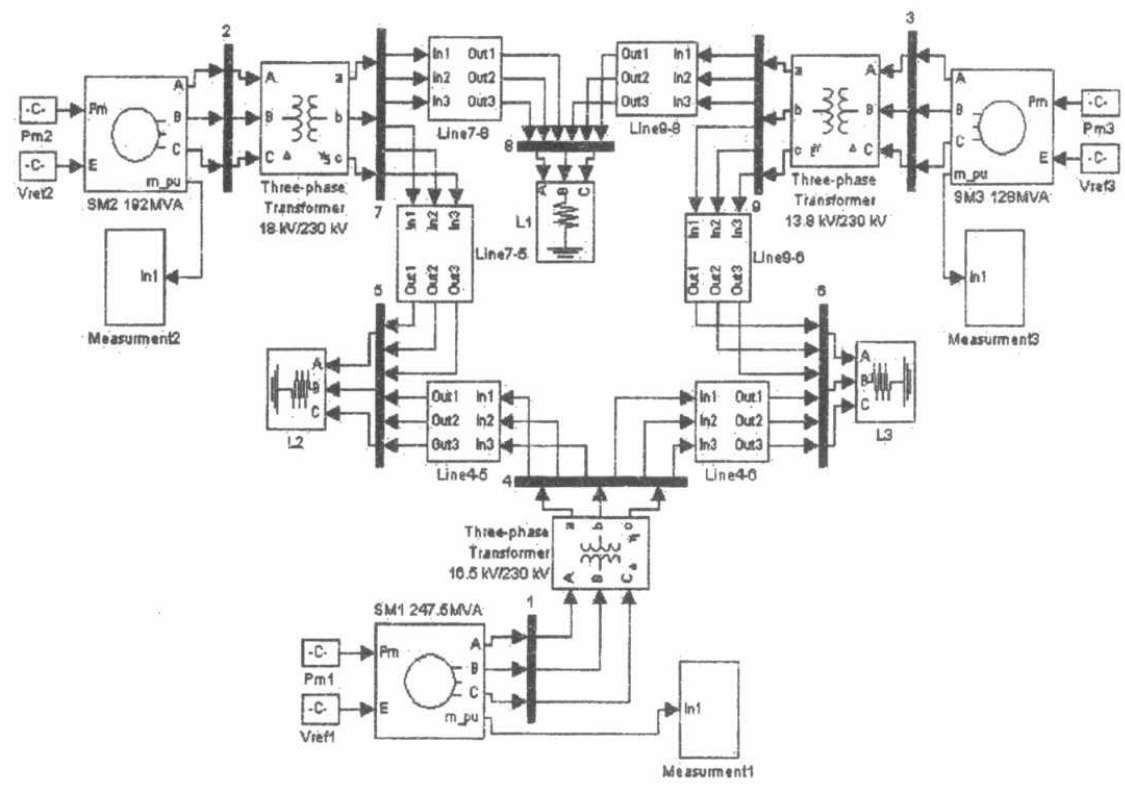

Fig.4 Representation of Case study(2) by Matlab-Power system toolbox 